\title{
Discordant Splitting Capacitance Drives System Bus Voltage Pulsation Suppression
}

\author{
Honglin Zhu ${ }^{1)}$, Chao Zhang ${ }^{1 \mathrm{a})}$, and Jing $\mathrm{Xia}^{2}$
}

\begin{abstract}
This paper analyzes the power decoupling performance of the mismatched split-capacitor half-bridge circuit, and reveals the mechanism of fundamental harmonic generation in the circuit through the mathematical model of the decoupling circuit established. In order to solve this problem, firstly, this paper proposes a control strategy of introducing DC bias coefficient on the basis of instantaneous voltage control of split capacitor $\mathrm{C}_{1}$. Secondly, using instantaneous voltage of capacitor $\mathrm{C}_{1}$ as control quantity can better realize voltage tracking control effect, with fast response speed and simple control. Finally, the effectiveness of this control strategy is verified by experiments.
\end{abstract}

key words: Split capacitor structure, capacitance mismatch, PR control, instantaneous voltage control

Classification: Power devices and circuits, Circuits and hardware

\section{Introduction}

Permanent Magnet Synchronous Motor (PMSM) is widely used in the industry and household appliances due to its advantages of simple structure, convenient maintenance and high power density $[1,2]$. The conventional PMSM driver requires a large capacity electrolytic capacitor to keep the bus voltage stable $[3,4]$. However, it is easy to cause the failure of the drive system due to the shortcoming of short life and large volume of electrolytic capacitor [5, 6, 7, 8]. So, it is replaced by the thin film capacitor. This system is called Electrolytic Capacitor Less (ECL) driver. However, ECL motor drive systems suffer from higher torque ripple, lower grid quality, and lower efficiency due to the reduction of the DC-link capacitor $[9,10]$.

In order to solve the above problems, some scholars proposed a method of using active power decouples the circuits $[11,12,13,14]$. According to the topological structures of the circuits, they can usually be divided into two categories, namely, parallel compensation circuits $[15,16,17,18]$ and series compensation circuits $[19,20]$. The advantage of series compensation circuit is that it can be constructed with

\footnotetext{
${ }^{1}$ Dept. of Electrical Engineering, Jiangsu University, Jiangsu 212013, China

${ }^{2}$ Dept. of Computer Science and Communication Engineering, Jiangsu University 212013, China

a) 13945463080@163.com
}

DOI: $10.1587 /$ elex.19.20220041

Received January 22, 2022

Accepted February 01, 2022

Publicized March 07, 2022 low voltage components and only needs to deal with part of the ripple power. In this case, high conversion efficiency can be preserved. However, the DC link would be limited, and it is not suitable for working under the condition of high AC line. Yet, parallel decoupling often uses independent decoupling circuits in parallel on the DC-Link, which have the characteristics of high adaptability and flexible composition. The parallel decoupling is suitable for both rectification and inverter power flow directions. So, the parallel compensation circuit is widely used.

In order to improve the efficiency of power decoupling, The literature $[21,22,23,24]$ proposed a closed-loop feedback control method of DC bus voltage, which had a good effect in suppressing bus voltage ripple and improving decoupling accuracy. Literature [25] proposed a half-bridge decoupling circuit based on DC split capacitor as shown in Figure 1, which had several advantages of parallel decoupling circuit. In literature [26, 27], the power decoupling strategy of pulsating DC voltage feedback control was introduced. The control idea was using orthogonal transformation to reduce the secondary ripple voltage error of rectifier to primary ripple, and using proportional resonance controller to control the error and generate half-bridge circuit modulation signal. Literature [28] used a method applying direct power control to control the feedback DC pulsating voltage, which had the ability to suppress the harmonics in the DC voltage.

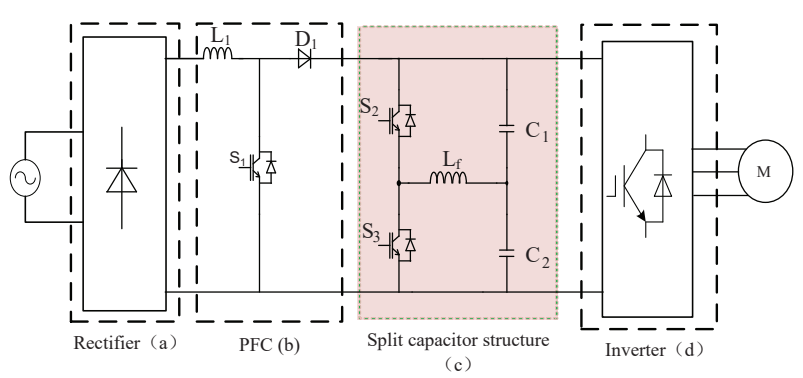

Fig. 1. Half-bridge power decoupling circuit

However, the premise of bus voltage control in the above literatures are $C_{1}=C_{2}=C_{f}$ In the actual operation state, the film capacitor would be affected by humidity, time effect and other factors, resulting in $20 \%$ capacitance offset. In the circuit, its fundamental wave amplitude can reach 100 
$\mathrm{V}$, accounting for $5 \%$ of the system output power. It can be seen that the influence caused by capacitor deviation cannot be ignored $[29,30]$. The variation of capacitor parameters will lead to a larger deviation between the compensated secondary power pulsation and the calculated power parameters; simultaneously generate other frequencies of harmonics. It will reduce the power decoupling performance, lead to capacitor voltage distortion, and make the original control difficult to effectively suppress the bus voltage fluctuation. For the problem of capacitance deviation, this paper analyzes the power decoupling performance of the half-bridge circuit when the capacitance deviation of the splitting capacitor occurs. By establishing the theoretical derivation of the decoupling circuit, it reveals the mechanism of generating a harmonic power in the circuit. To solve this problem, in this paper, a new control strategy is proposed, in which DC compensation is introduced on the basis of capacitor $\mathrm{C}_{1}$ instantaneous voltage control to suppress the DC-Link fluctuations. This control strategy improves the stability of the system. Finally, the proposed control strategy is verified by experiments, and the results are consistent with the theoretical analysis.

\section{Harmonic Analysis of Pulsating Power in Capacitance Deviation Decoupling Circuit}

In the active power decoupling circuit shown in Fig. 1. The split capacitors $\mathrm{C}_{1}$ and $\mathrm{C}_{2}$ form a DC-Link capacitor, and the split point is connected with the midpoint of the bridge arm of the half bridge circuit composed of $S_{2}$ and $S_{3}$ through inductance $L_{f}$ to form a decoupling loop.

When the circuit operates, the voltages of capacitors $C_{1}$ and $\mathrm{C}_{2}$ complement each other, so as to realize no pulsation of DC-link voltage.

The grid voltage and current are defined as

$$
\begin{aligned}
& u_{g}(t)=U_{g} \sin (\omega t) \\
& i_{g}(t)=I_{g} \sin (\omega t)
\end{aligned}
$$

where $U_{g}$ and $I_{g}$ are the amplitudes of grid voltage and rectifier input current. Because the energy stored in the inductor is small, it can be ignored. The instantaneous input power $P_{a c}$ at the AC side of the rectifier can be expressed as

$$
\begin{aligned}
P_{g} & =u_{g}(t) i_{g}(t) \\
& =\frac{U_{g} I_{g}}{2}-\frac{U_{g} I_{g}}{2} \cos (2 \omega t)
\end{aligned}
$$

It can be seen from (2) that $P_{a c}$ contains only secondary pulsation power and DC component.

In the decoupling circuit, the voltage references of the split capacitors are expressed as follows

$$
\begin{aligned}
& u_{c 1}=U_{C 1}+B \cos (\omega t+\theta) \\
& u_{c 2}=U_{C 2}+B \cos (\omega t+\theta)
\end{aligned}
$$

where $U_{c 1}$ and $U_{c 2}$ are the DC biases of the split capacitor voltages respectively, $B$ is the amplitude of AC component of split capacitor voltages, $\theta$ is the initial phase, $\omega$ is the angular frequency. The currents flowing through the capacitors are

$$
\begin{aligned}
& i_{c 1}(t)=C_{1} \frac{d u_{c 1}(t)}{d_{t}}=\omega C_{1} B \cos (\omega t+\theta) \\
& i_{c 2}(t)=C_{2} \frac{d u_{c 2}(t)}{d_{t}}=-\omega C_{2} B \cos (\omega t+\theta)
\end{aligned}
$$

According to Kirchhoff's Law (KCL), the current of inductor $L_{f}$ in decoupling circuit can be obtained

$$
i_{L_{f}}(t)=-\left(C_{1}+C_{2}\right) \omega B \cos (\omega t+\theta)
$$

Because the energy stored in inductor is small, the decoupling circuit power can be considered to be equal to the instantaneous power $P_{c}$ of $\mathrm{C}_{1}$ and $\mathrm{C}_{2}$, which can be expressed as

$$
\begin{aligned}
& p_{c}(t)=u_{C 1}(t) i_{C 1}(t)+u_{C 2}(t) i_{C 2}(t) \\
& =\left(C_{1} U_{C 1}-C_{2} U_{C 2}\right) \omega B \cos (\omega t+\theta)+ \\
& \frac{1}{2}\left(C_{1}+C_{2}\right) \omega C_{f} B^{2} \sin (2 \omega t+2 \theta)
\end{aligned}
$$

where $\mathrm{C}_{1}$ is equal to $\mathrm{C}_{2}$ under ideal conditions. Therefore, the decoupling circuit can effectively absorb the pulsating power of the power grid. However, the capacitance values of $\mathrm{C}_{1}$ and $\mathrm{C}_{2}$ will change due to humidity, time effect and other factors, resulting in increased DC-Link fluctuation. In order to analyze the specific influence of capacitance deviation on the performance of decoupling circuit, capacitance deviation is set for capacitor $\mathrm{C}_{1}$

$$
\left\{\begin{array}{l}
C_{1}=m C_{2} \\
C_{2}=C_{f}
\end{array}\right.
$$

where $C_{f}$ is the design capacitance and $m$ is the deviation coefficient of split capacitance. It can be seen from (6) that the decoupling circuit contains primary pulsating power and secondary pulsating power in case of capacitance deviation. According to the power balance theory, the secondary power of the power grid is absorbed by the decoupling circuit, which means the quadratic terms of (6) and those of (2) are equal. The phase and amplitude of the AC component of the split capacitor voltages are further solved when $m \neq 1$.

$$
\begin{aligned}
& \theta= \pm \frac{\pi}{2}+\frac{1}{2} \arctan t \frac{-U_{g}}{\omega L_{1} I_{g}}
\end{aligned}
$$

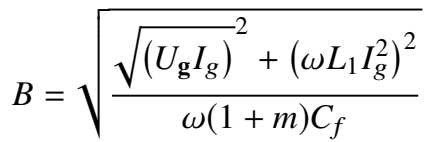

It can be seen from (8) and (9) that when the capacitance values deviate, the phases of split capacitors $C_{1}$ and $C_{2}$ remain unchanged, but the amplitudes change.

When the capacitance is equal, the power balance relationship of the circuit is

$$
P_{g}=P_{m}+P_{c}
$$


where $P_{m}$ is the instantaneous power of the motor. When the capacitance values are offset, it can be further seen from (6) that the original power balance relationship is broken, and the circuit power balance relationship is

$$
P_{g}=P_{m}+P_{C}+P_{1}
$$

where $P_{1}$ is the primary pulsating power derived from the capacitance deviation. Due to the capacitance deviation, the active power decoupling circuit cannot absorb the primary pulsating power. The primary pulsating power is transmitted to the DC side, resulting in DC-Link voltage fluctuation.

Fig. 2 is a voltage waveform under the condition of splitting capacitor $\mathrm{C}_{1}=1.2 \mathrm{C}_{2}(\mathrm{~m}=1.2)$ based on the conventional control strategy. It can be seen that the DC voltage includes the fundamental AC voltage component under the condition of capacitance deviation, which increasing the DC-Link voltage fluctuation.

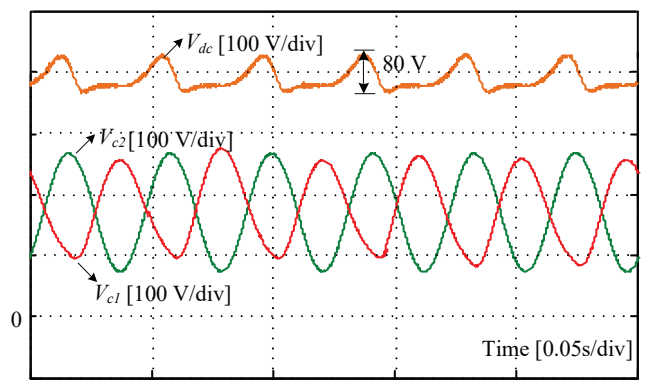

(a)

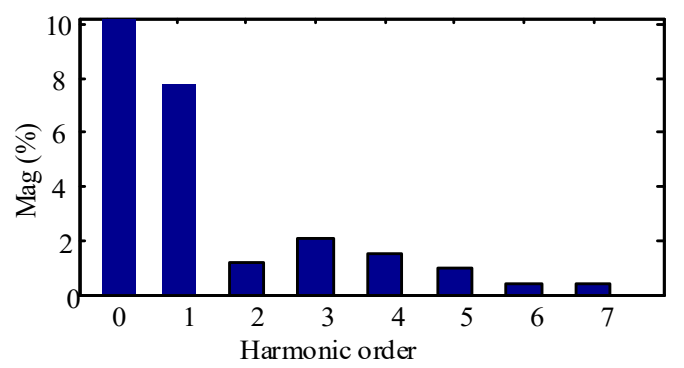

(b)

Fig. 2. Simulation of traditional control in case of capacitance deviation. (a) Half bridge decoupling circuit waveform. (b) DC-link voltage spectrum

\section{Split capacitor Control Strategy}

Because of the capacitance deviation, the DC-Link voltage contains the primary pulsating power. In order to eliminate the primary pulsating power, this paper delays the pulsating power $P_{\mathrm{c}}$ of the decoupling circuit by 90 degree. Then, the $P_{\mathrm{c}}$ and the delayed signal are calculated by the orthogonal transformation matrix, so that the fundamental harmonic in the $P_{\mathrm{c}}$ is reduced to a DC component, and the second harmonic is reduced to a fundamental wave. The transformation matrix is as follows

$$
T_{r}=\left[\begin{array}{cc}
\cos (\omega t) & \sin (\omega t) \\
-\sin (\omega t) & \cos (\omega t)
\end{array}\right]
$$

According to (2) and (10), it can be concluded that the decoupling power $P_{\mathrm{c}}$ is equal to the pulsating power output by the power grid, and the capacitor power is based on the voltage, so the pulsating decoupling power $P_{\mathrm{c}}$ is reduced to the pulsating fundamental voltage $U_{\mathrm{c}}$

$$
\begin{aligned}
U_{c}= & \frac{1}{2}\left(C_{1} U_{c 1}-C_{2} U_{c 2}\right) \omega B \\
& +\frac{1}{2}\left(C_{1}+C_{2}\right) \omega B^{2} \cos (\omega t+\theta)
\end{aligned}
$$

The DC coefficient of $U_{\mathrm{c}}$ is caused by capacitance deviation, and the fundamental wave is the power grid pulsation. Under the condition of equal capacitance, the error voltage $U_{\mathrm{c}}$ only contains the fundamental component. The voltage passes through PR controller to generate current reference value $i_{\mathrm{Lf}}^{*}$, then, compared with the actual inductor current. Because the waveform of inductor current is sinusoidal, PR controller is used to adjust and then control the modulation signals $S_{2}$ and $\mathrm{S}_{3}$ output.

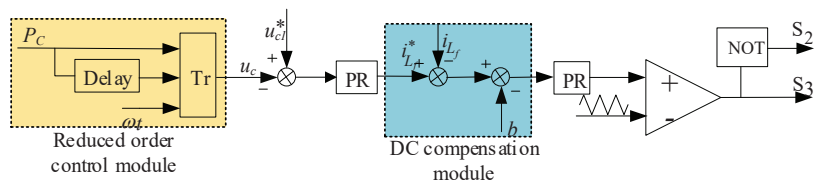

Fig. 3. Diagram of the proposed control strategy

In order to suppress the fundamental harmonic caused by capacitance deviation, this paper introduces additional DC bias coefficient $b$ to eliminate the DC component of the fundamental harmonic after order reduction. The relationship between the splitting capacitor voltages and the DC-Link voltage can be expressed as

$$
\left\{\begin{array}{c}
U_{C 1}=(1-b) U_{d c} \\
U_{C 2}=b U_{d c}
\end{array}\right.
$$

$U_{\mathrm{dc}}$ is the average value of DC-Link voltage, $\mathrm{b}$ is the dc bias coefficient. Since the splitting capacitor voltages fluctuate between 0 and $U_{\mathrm{dc}}$, the maximum and minimum capacitor voltages should meet the following relationship

$$
\begin{aligned}
& U_{C 1 \text { max }}=U_{c 1}+B<V_{\mathrm{dc}} \\
& U_{C 2 \text { min }}=U_{c 2}-B>0
\end{aligned}
$$

Substitute (14) into (15) to obtain

$$
b U_{d c}>B
$$

Substitute (9) into (16) to obtain

$$
\frac{U_{g} I_{g}}{\omega(1+m) C_{f}}-b^{2} U_{d c}^{2}<0
$$

The above formula is the unary quadratic inequality of DC bias coefficient $b$, and the extreme value of $b$ can be expressed as 


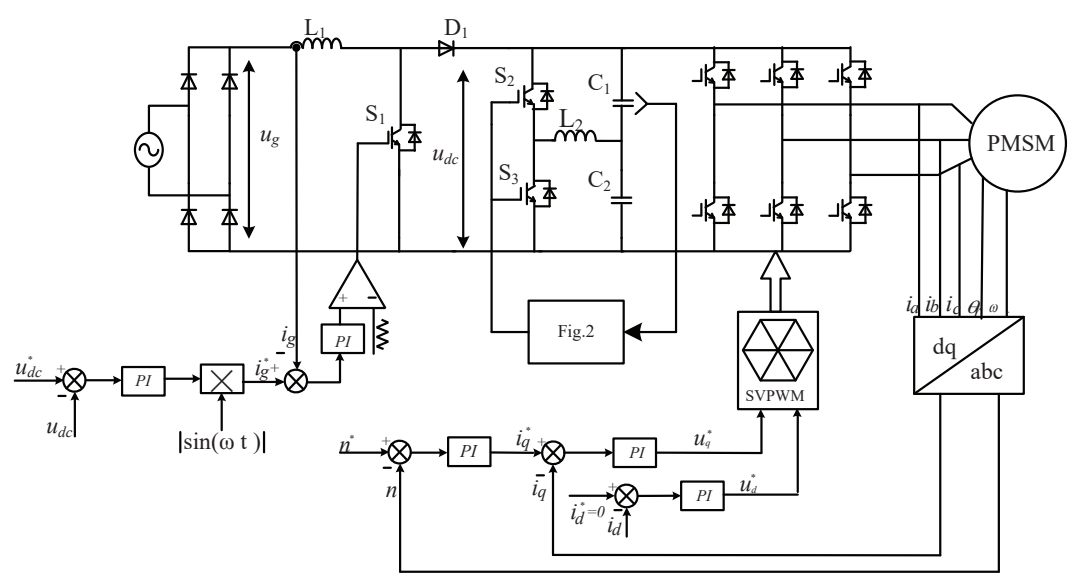

Fig. 4. ECL drive system of total control strategy.

$$
b= \pm \sqrt{\frac{U_{g} I_{g}}{U_{d c}^{2} \omega C_{f}(1+m)}}
$$

In this paper, the capacitance deviation coefficient is set as $\mathrm{m}=1.2$. According to (13), it can be seen that the DC bias is positive, so $b=+0.5$. The Specific control is shown in Figure 3.

The PR controller is used to realize $i_{\mathrm{Lf}}$ tracking $i_{\mathrm{Lf}}^{*}$ without static error and high-power operation of circuit, and its controller transfer function is as follows

$$
G_{P R}(s)=K_{p}+K_{R} \frac{2 \omega_{c} s}{s^{2}+2 \omega_{c} s+\omega}
$$

where $K_{P}$ is the proportional coefficient, $K_{R}$ is the resonance coefficient, $\omega_{\mathrm{c}}$ is the cut-off frequency.

\section{Experimental results}

In order to verify the feasibility of the proposed control strategy, an experimental platform was built. The main component parameters of the ECL drive system are shown in Table I. The control part of the experimental circuit is realized in DSPACEDS1006 semi-physical simulation platform.

Table I. Key parameters of the ECL motor drive.

\begin{tabular}{l|l}
\hline Parameters & Values \\
\hline Inductance & $2 \mathrm{mH}$ \\
\hline Switching frequency & $10 \mathrm{kHz}$ \\
\hline Grid frequency & $50 \mathrm{~Hz}$ \\
\hline $\mathrm{C}_{\mathrm{f}}$ & $90 \mu \mathrm{F}$ \\
\hline $\mathrm{m}$ & 1.2 \\
\hline DC-link voltage & $380 \mathrm{~V}$ \\
\hline Rated power & $0.4 \mathrm{~kW}$ \\
\hline Rated torque & $5 \mathrm{~N} \cdot \mathrm{m}$ \\
\hline
\end{tabular}

Fig 4 shows the control scheme block diagram of the ECL motor driver, which includes PFC control, PMSM vector control and DC link instantaneous voltage stability control. Fig. 5 and Fig. 6 show the experimental wave-forms under the traditional control strategy and the proposed control strategy respectively. The traditional control strategy can not eliminate the first harmonic caused by capacitance deviation, so the power grid current behind the power grid voltage. However, in this paper, the order reduction module is used to reduce the order of the first harmonic caused by capacity deviation to DC bias, and eliminate the bias through DC compensation link, and control the power grid current to track the power grid voltage. The results show that when the control strategy proposed in this paper is adopted, the grid voltage and current can be well controlled in phase, and the motor speed and torque are more stable.

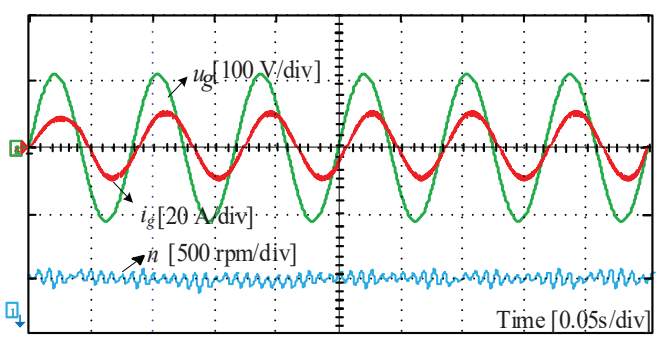

(a)

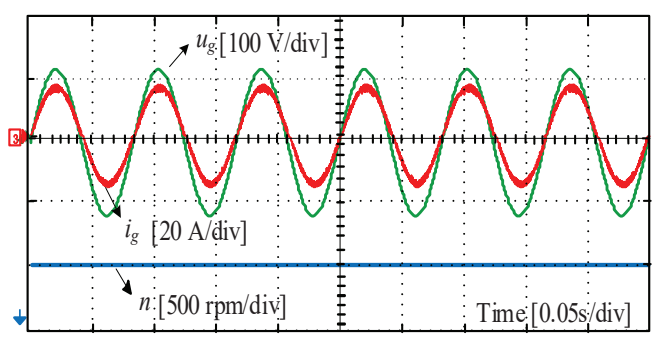

(b)

Fig. 5. Experimental waveform of the motor drive system. $n=1000 \mathrm{rpm}$ and Te $=5$ N.m (a) traditional ECL motor drives system. (b) the proposed ECL motor drives system.

It can be seen from Fig. 7 that the voltage of the split capacitor under traditional control cannot be completely complementary, and the decoupling performance declines, resulting the 


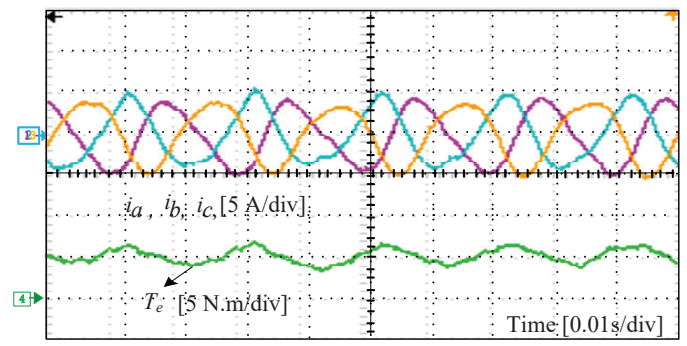

(a)

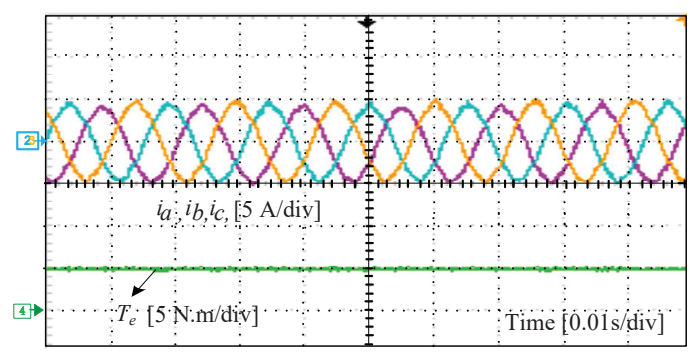

(b)

Fig. 6. Experimental waveform of motor torque $\mathrm{Tm}$ and three-phase motor currents $i_{\mathrm{a}}, i_{\mathrm{b}}, i_{\mathrm{c}}$ with the $\mathrm{n}=1000 \mathrm{rpm}, \mathrm{Te}=5 \mathrm{~N} . \mathrm{m}$ (a) traditional ECL motor drives system. (b) Proposed ECL motor drives system.

DC-Link voltage fluctuation of $90 \mathrm{~V}$. However, the proposed control strategy can effectively control the split capacitor voltages complementary, and effectively restrain the fluctuation of bus voltage within $20 \mathrm{~V}$, with the suppression effect being improved by about $78 \%$.

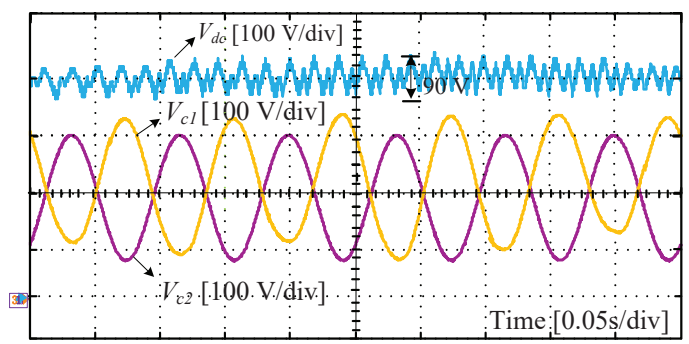

(a)

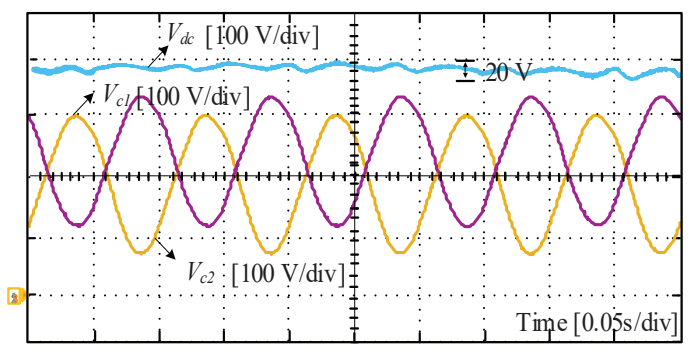

(b)

Fig. 7. Experimental waveform of split capacitor voltage and DC-link voltage. (a) traditional ECL motor drives system. (b) Proposed ECL motor drives system.

Fig. 8 shows that the ac component of DC-link voltage is very small and can be ignored basically. The harmonic content of power grid current $i_{\mathrm{g}}$ meets the IEC 61000-3-2 standard. The experimental results accord with the theoretical analysis and verify the effectiveness of the proposed optimal control structure.

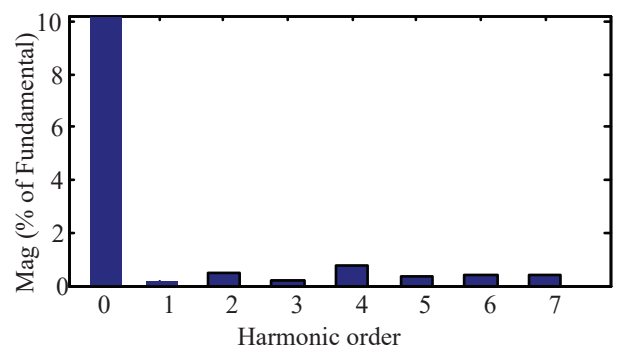

(a)

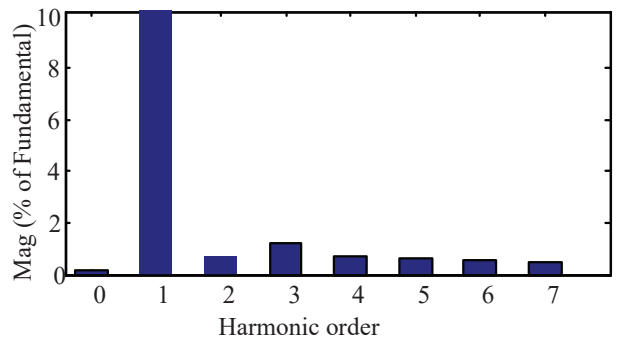

(b)

Fig. 8. Experimental waveform of (a) spectrum of $u_{\mathrm{dc}}$ and (b) spectrum of $i_{\mathrm{g}}$

\section{Conclusion}

In this paper, a new control method is proposed to suppress DC-Link fluctuation under capacitance deviation condition. Firstly, the harmonic analysis of capacitance bias split capacitor structure is proposed. Then, the power decoupling relation is used to eliminate the second harmonic in the system, and the fundamental wave caused by the capacitance deviation is eliminated by a given DC bias coefficient. Finally, the effectiveness of the proposed control strategy is verified by experimental results.

\section{Acknowledgments}

This work was supported in part by the National Natural Science Foundation of China under Grant 52077098. and in part by the Priority Academic Program Development of Jiangsu Higher Education Institutions under Grant PAPD2018-87.(Corresponding author: Chao Zhang).

\section{References}

[1] X. Zhu, Y. Yuan, Y. Zuo, X. Bu and B. Shi, "Phase-Shift Decoupled SVPWM Control Strategy for Open Winding Permanent Magnet Synchronous Motor with Common DC Bus," 2018 IEEE Energy Conversion Congress and Exposition (ECCE), Portland, OR, USA, 2018, pp. 34213427.(DOI: 10.1109 /ECCE.2018.8557992).

[2] L. Xu, X. Zhu, L. Zhang, C. Zhang and D. Fan, "Two-axis Vector Control of Double Stator Linear and Rotary Permanent Magnet Machine Considering Orthogonally Coupling Effect," 2020 IEEE Energy Conversion Congress and Expo- 
sition (ECCE), Detroit, MI, USA, 2020, pp. 533-539.(DOI: 10.1109/ECCE44975. 2020.9236144) .

[3] X. Zhu, Z. Xiang, C. Zhang, L. Quan, Y. Du and W. Gu, "CoReduction of Torque Ripple for Outer Rotor Flux-Switching PM Motor Using Systematic Multi-Level Design and Control Schemes," in IEEE Transactions on Industrial Electronics, 64 (2017) 1102 (DOI:10.1109/TIE.2016.2613058).

[4] H. Wang and F. Blaabjerg, "Reliability of Capacitors for DC-Link Applications in Power Electronic Converters-An Overview," in IEEE Transactions on Industry Applications, 50 (2014) 3569 (DOI:10.1109/TIA.2014.2308357).

[5] C. Zhang, L. Xu, X. Zhu, Y. Du and L. Quan, "Torque Ripple Reduction of PMSM With Small Capacitor Drive Systems Based on Combined Control Method," in IEEE Access, 9 (2021) 98874 (DOI:10.1109/ACCESS.2021.3095665).

[6] C. Zhang, L. Xu, X. Zhu, Y. Du and L. Quan, "Elimination of DC-Link Voltage Ripple in PMSM Drives With a DC-Split-Capacitor Converter," in IEEE Transactions on Power Electronics, 36 (2021) 8141 (DOI:10.1109/TPEL.2020.3048183).

[7] Sun Quan, Wang Youren, Jiang Yuanyuan, et al. A novel approach of health condition assessment for boost converters under variable temperature conditions[J]. Transactions of China Electrotechnical Society, 2018, 33(6): 1364-1373.

[8] A. Satoh and S. Suzuki: "Future of electronics," submitted to IEICE Trans. Electron.

[9] Electromagnetic Compatibility (EMC): Limits-Limits for Harmonic Current Emissions, Standard IEC 61000-3-2, Part 3-2, 2005.

[10] D. Edwards: in Handbook of Optical Constants of Solids, ed. E. Palik (Academic Press, New York, 1985) 547-549.

[11] S. Li, W. Qi, S. Tan and S. Y. R. Hui, "A Single-Stage Two-Switch PFC Rectifier With Wide Output Voltage Range and Automatic AC Ripple Power Decoupling," in IEEE Transactions on Power Electronics, 32 (2017) 6971 (DOI: 10.1109/TPEL.2016. 2622980).

[12] H. Shin, Y. Chae, Y. Son and J. Ha, "Single-Phase GridConnected Motor Drive System With DC-Link Shunt Compensator and Small DC-Link Capacitor," in IEEE Transactions on Power Electronics, 32 (2017) 1268(DOI:10.1109/ TPEL .2016.2540633).

[13] Y. Son and J. Ha, "Discontinuous Grid Current Control of Motor Drive System With Single-Phase Diode Rectifier and Small DC-Link Capacitor," in IEEE Transactions on Power Electronics, 32 (2017) 1324 (DOI:10.1109/TPEL.2016.2544400)

[14] W. Liu, K. Wang, H. S. Chung and S. T. Chuang, "Modeling and Design of Series Voltage Compensator for Reduction of DC-Link Capacitance in Grid-Tie Solar Inverter," in IEEE Transactions on Power Electronics,30 (2015) 2534 (DOI:10.1109/TPEL.2014. 2336856).

[15] X. Cao, Q. Zhong and W. Ming, "Ripple Eliminator to Smooth DC-Bus Voltage and Reduce the Total Capacitance Required," in IEEE Transactions on Industrial Electronics, 62 (2015) 2224 (DOI:10.1109/TIE.2014.2353016).

[16] W. Cai, L. Jiang, B. Liu, S. Duan and C. Zou, "A power decoupling method based on four-switch three-port DC/DC/AC converter in DC microgrid," 2013 IEEE Energy Conversion Congress and Exposition, Denver, CO, USA, 20134678 (DOI:10.1109/ECCE.2013.6647328).

[17] J. He, X. Ruan and L. Zhang, "Adaptive Voltage Control for Bidirectional Converter in Flicker-Free Electrolytic Capacitor-Less AC-DC LED Driver," in IEEE Transactions on Industrial Electronics, 64 (2017) 320 (DOI: 10.1109/TIE.2016.2608767).

[18] Y. Liu, Y. Sun, M. Su, M. Zhou, Q. Zhu and X. Li, "A SinglePhase PFC Rectifier With Wide Output Voltage and Low-
Frequency Ripple Power Decoupling," in IEEE Transactions on Power Electronics, 33 (2018) 5076 (DOI:10.1109/TP EL. 2017.2734088).

[19] H. Hu, S. Harb, N. Kutkut, I. Batarseh and Z. J. Shen, "A Review of Power Decoupling Techniques for Microinverters With Three Different Decoupling Capacitor Locations in PV Systems," in IEEE Transactions on Power Electronics, 28 (2013) 2711 (DOI:10.1109/TPEL.2012.2221482).

[20] M. A. Vitorino, L. F. S. Alves, R. Wang and M. B. de Rossiter Corrêa, "Low-Frequency Power Decoupling in Single-Phase Applications: A Comprehensive Overview," in IEEE Transactions on Power Electronics, 32 (2017) 2892 (DOI:10.1109/TPEL.2016. 2579740).

[21] W. Qi, S. Li, Siew-Chong-Tan and S. Y. R. Hui, "A two-switch buck-boost PFC rectifier with automatic AC power decoupling capability," 2016 IEEE Energy Conversion Congress and Exposition (ECCE), Milwaukee, WI, USA, 2016 1-7. (DOI: 10.1109/ECCE.2016.7854798).

[22] Y. Tang and F. Blaabjerg, "A Component-Minimized SinglePhase Active Power Decoupling Circuit With Reduced Current Stress to Semiconductor Switches," in IEEE Transactions on Power Electronics, 30 (2015) 2905 (DOI: 10.1109/TPEL.2014. 2369959).

[23] H. Zhao, H. Li, C. Min and K. Zhang, "A modified singlephase h-bridge PWM rectifier with power decoupling," IECON 2012 - 38th Annual Conference on IEEE Industrial Electronics Society, Montreal, QC, Canada, 201280 (DOI:10.1109/IECON.2012. 6388691).

[24] W. Yao, X. Wang, P. C. Loh, X. Zhang and F. Blaabjerg, "Improved Power Decoupling Scheme for a SinglePhase Grid-Connected Differential Inverter With Realistic Mismatch in Storage Capacitances," in IEEE Transactions on Power Electronics, 32 (2017) 186 (DOI: 10.1109/TPEL.2016.2525789).

[25] Y. Tang, F. Blaabjerg, P. C. Loh, C. Jin and P. Wang, "Decoupling of Fluctuating Power in Single-Phase Systems Through a Symmetrical Half-Bridge Circuit," in IEEE Transactions on Power Electronics, 30 (2015) 1855 (DOI: 10.1109/TPEL.2014. 2327134).

[26] Y. Tang, Z. Qin, F. Blaabjerg and P. C. Loh, "A Dual Voltage Control Strategy for Single-Phase PWM Converters With Power Decoupling Function," in IEEE Transactions on Power Electronics, 30 (2015) 7060 (DOI:10.1109/TPEL.2014.2385032).

[27] S. Li, W. Qi, S. Tan and S. Y. Hui, "Integration of an Active Filter and a Single-Phase AC/DC Converter With Reduced Capacitance Requirement and Component Count," in IEEE Transactions on Power Electronics, 31 (2016) 4121 (DOI:10.1109/TPEL.2015. 2476361).

[28] W. Yao, X. Wang, P. C. Loh, X. Zhang and F. Blaabjerg, "Improved Power Decoupling Scheme for a Single-Phase GridConnected Differential Inverter With Realistic Mismatch in Storage Capacitances," in IEEE Transactions on Power Electronics, 32 (2017) 186 (DOI:10.1109/TPEL.2016.2525789).

[29] W. Yao, P. C. Loh, Y. Tang, X. Wang, X. Zhang and F. Blaabjerg, "A Robust DC-Split-Capacitor Power Decoupling Scheme for Single-Phase Converter," in IEEE Transactions on Power Electronics, 32 (2017) 8419 (DOI: 10.1109/TPEL.2016.2645800).

[30] Y. Tang, W. Yao, H. Wang, P. C. Loh and F. Blaabjerg, "Transformerless photovoltaic inverters with leakage current and pulsating power elimination," 2015 9th International Conference on Power Electronics and ECCE Asia (ICPE-ECCE Asia), Seoul, Korea (South), 2015115 (DOI: 10.1109/ICPE.2015.7167774). 